\title{
Regional and socio-economic differences in food, nutrient and supplement intake in school-age children in Germany: results from the GINIplus and the LISAplus studies
}

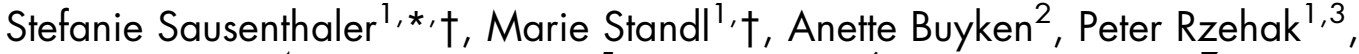 \\ Sibylle Koletzko ${ }^{4}$, Carl Peter Baver ${ }^{5}$, Beate Schaaf6, Andrea von Berg7, \\ Dietrich Berdel ${ }^{7}$, Michael Borte ${ }^{8,9}$, Olf Herbarth ${ }^{10}$, Irina Lehmann ${ }^{11}$, Ursula Krämer ${ }^{12}$, \\ H-Erich Wichmann ${ }^{1,2}$ and Joachim Heinrich ${ }^{1} \ddagger$ for the GINIplus and the \\ LISAplus Study Groups \\ 'Helmholtz Zentrum München, German Research Center for Environmental Health, Institute of Epidemiology, \\ Ingolstädter Landstr. 1, 85764 Neuherberg, Germany: ${ }^{2}$ Research Institute of Child Nutrition, University of Bonn, \\ Dortmund, Germany: ${ }^{3}$ Institute of Medical Data Management, Biometrics and Epidemiology, Ludwig-Maximilians- \\ University of Munich, Munich, Germany: ${ }^{4}$ Dr von Hauner Children's Hospital, Ludwig-Maximilians-University \\ of Munich, Munich, Germany: ${ }^{5}$ Department of Pediatrics, Technical University of Munich, Munich, Germany: \\ ${ }^{6}$ Medical Practice for Pediatrics, Bad Honnef, Germany: ${ }^{7}$ Department of Pediatrics, Marien-Hospital Wesel, \\ Wesel, Germany: ${ }^{8}$ Department of Pediatrics, University of Leipzig, Leipzig, Germany: ${ }^{9}$ Municipal Hospital \\ 'St. Georg' Leipzig, Children's Hospital, Leipzig, Germany: ${ }^{10}$ Faculty of Medicine, Environmental Hygiene and \\ Environmental Medicine, University of Leipzig, Leipzig, Germany: " \\ Helmholtz Centre for Environmental Research - UFZ, Leipzig, Germany: ${ }^{12}$ Institut für Umweltmedizinische \\ Forschung, University of Düsseldorf, Düsseldorf, Germany
}

Submitted 1 March 2010: Accepted 23 November 2010: First published online 31 January 2011

\begin{abstract}
Objective: To describe regional differences between eastern and western Germany with regard to food, nutrient and supplement intake in 9-12-year-old children, and analyse its association with parental education and equivalent income.

Design: Data were obtained from the 10-year follow-up of the two prospective birth cohort studies - GINIplus and LISAplus. Data on food consumption and supplement intake were collected using an FFQ, which had been designed for the specific study population. Information on parental educational level and equivalent income was derived from questionnaires. Logistic regression modelling was used to analyse the effect of parental education, equivalent income and region on food intake, after adjusting for potential confounders.

Setting: Germany.

Subjects: A total of 3435 children aged 9-12 years.

Results: Substantial regional differences in food intake were observed between eastern and western Germany. Intakes of bread, butter, eggs, pasta, vegetables/salad and fruit showed a significant direct relationship with the level of parental education after adjusting for potential confounders, whereas intakes of margarine, meat products, pizza, desserts and soft drinks were inversely associated with parental education. Equivalent income had a weaker influence on the child's food intake. Conclusions: Nutritional education programmes for school-age children should therefore account for regional differences and parental education.
\end{abstract}

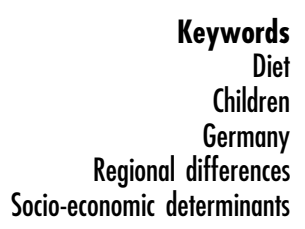

words

Children

Germany Socio-economic determinants
In Germany, in the early 1990s, shortly after reunification, substantial differences in diet between the eastern and western parts were reported in adults ${ }^{(1)}$. Although food

$\dagger$ Both authors have contributed equally to the manuscript.

\$ Members of and institutions affiliated with the LISAplus and the GINIplus study groups are listed in the Appendix. consumption patterns have since largely converged, differences still existed in $1998^{(2)}$ and hence they probably do even today.

Furthermore, socio-economic inequalities in food choice and dietary intakes have been reported constantly in the past ${ }^{(3-6)}$. These studies supported the hypothesis that people from higher socio-economic classes have higher 
intakes of healthy foods, such as whole grains, fish, low-fat dairy products, fresh fruit and vegetables, and lower intakes of unfavourable foods, such as meat and added fat, and were thus more likely meet dietary recommendations than people from lower socio-economic classes. Although these associations have been studied mainly in adults, as reviewed recently ${ }^{(7)}$, it is less clear how parental socio-economic position influences food intake in school-age children. In this context, it would be worth knowing whether and how dietary supplement use in children depends on parental education and household income, as this has become common in German children and adolescents over the past years ${ }^{(8)}$. According to the German Health Interview and Examination Survey for Children and Adolescents (KiGGS), $15 \%$ of $12-13$-year-old boys and $23 \%$ of $12-13$-year-old girls were taking dietary supplements in $2006^{(9)}$. Educational inequalities were found; however, as most dietary supplements are quite expensive, household income is likely to further limit supplement intake in children.

Detailed knowledge of dietary differences associated with socio-economic inequalities or region of living has important implications, both for the analysis of epidemiological studies and for improving interventions to promote healthy eating. Therefore, the aim of the present study was to describe potential differences between eastern and western Germany and the effect of parental education and equivalent income on food, nutrient and supplement intake in our study population of 9-12-yearold children living in Germany.

We hypothesise that the intake of favourable foods in children, such as fruit and vegetables, as well as the intake of clearly unfavourable foods such as sweets and cakes, shows a social gradient, which is probably mainly determined by the level of parental education and equivalent income. We further hypothesise that, in addition to socio-economic differences, regional differences between eastern and western Germany exist for particular foods and food groups.

\section{Methods}

\section{Study population}

Data from two ongoing German birth cohort studies were combined for the present analysis.

The GINIplus (German Infant Nutritional Intervention) study is a prospective birth cohort study that comprises the GINI intervention study (I) and the GINI non-intervention study (NI) and was initiated to investigate the influence of nutritional intervention during infancy, as well as that of air pollution and genetics on allergy development. Details on study design, recruitment and exclusion criteria have been described elsewhere ${ }^{(10,11)}$. In brief, between September 1995 and June 1998, a total of 5991 healthy full-term newborns were recruited from obstetric clinics in two regions of Germany (urban Munich and rural Wesel).
Group I ( $n$ 2252) included infants with a family history of allergy. In this prospective, double-blind intervention trial, newborns were randomized at birth to one of three hydrolysed formulae or to a conventional cow's milk formula. The formulae were provided only if the recommended exclusive breast-feeding for the first 4 months was not feasible or wanted. Infants with no family history of allergy ( $n$ 2507) or with a positive family history but from parents who refused to participate in the intervention trial ( $n$ 1232) were allocated to the NI group. This group was sent only the yearly questionnaires and did not receive any of the additional intervention procedures.

All children (I and NI groups) were followed up with identical questionnaires at 1, 2, 3, 4, 6 and 10 years of age to collect information on health outcomes and covariates, such as children's nutrition and other lifestyle factors. A total of 3317 children $(55.4 \%)$ of the original study population participated in the 10-year follow-up. Loss to followup was associated with a lower level of parental education, a negative history of parental atopy, the absence of atopic diseases in the child during the first 2 years of life and residency in Wesel; the presence of older siblings was not associated with discontinuation of the study.

The LISAplus study is a population-based birth cohort investigating influences of lifestyle-related factors on the immune system and the development of allergies in childhood'. Details on study design are described elsewhere $^{(12,13)}$. In brief, between November 1997 and January 1999, a total of 3097 newborns were initially recruited from four German cities: Munich, Leipzig, Wesel and Bad Honnef. Questionnaires on family history of atopy, parental education and other lifestyle factors were completed by parents shortly after delivery. Data on the child's health were collected by repeated parental-completed questionnaires at regular time intervals during the first 10 years $(0 \cdot 5,1,1 \cdot 5,2,4,6$ and 10 years of age). Since the 6-year follow-up, the influences of traffic emission and genetics on allergy development have become the focus of the study. A total of 1761 children (56.9\%) of the original study population participated in the 10-year follow-up. Loss to follow-up was strongly associated with a lower level of parental education and residency in Wesel or Leipzig, whereas the absence of older siblings, a negative history of parental atopy and absence of atopic diseases in the child during the first 2 years of life showed a weak association with discontinuation of the study.

In the 10-year follow-up of both studies, an FFQ was sent to all parents of children who completed the main questionnaire in advance and who indicated a willingness to participate in the dietary assessment. Since the FFQ was provided subsequent to the main questionnaire and only one written reminder was sent, the participation rate in the FFQ was overall $67 \cdot 9 \%$, based on participation in the 10-year main questionnaire. Subjects were excluded because of excessive missing information in the FFQ $(n 6)$ or because of implausible energy intake $(n 6)$. Thus, the 
present analysis is based on 3435 subjects from GINIplus ( $n$ 2190) and LISAplus ( $n$ 1245).

For both studies, approval from the local ethics committees (Bavarian General Medical Council, University of Leipzig, Medical Council of North-Rhine-Westphalia) and written consent from participant's families were obtained.

\section{FFQ}

The FFQ administered to parents was designed to measure children's usual food and nutrient intake over the past year, and more specifically to estimate energy, fatty acid and antioxidant intake at 10 years of age. The development including the selection process of the food item list and validation of the FFQ has been described previously ${ }^{(14)}$.

The FFQ comprised a list of eighty-two food items accompanied by several questions about the preferred fat and energy content of products, preparation methods, diets and food preferences, buying habits and dietary supplement use. To estimate how often food was consumed by their child on average over the previous year, parents were asked to choose one of nine frequency categories, ranging from 'never' to 'four times a day or more'. In addition, common portion sizes were assigned for each food item to enable an estimation of quantities. For food items that are difficult to describe in common household measures, coloured photographs from the EPIC (European Prospective Investigation into Cancer and Nutrition) study showing three different portion sizes were included ${ }^{(15)}$. The consumption frequencies and portion size estimates were converted into average consumption in $\mathrm{g} / \mathrm{d}$ and this information was linked to the German Food Code and Nutrient Database (BLS) version $\mathrm{II} \cdot 3 \cdot 1^{(16)}$. Where food portions were not illustrated by pictures, portion size data were obtained from a German list of portion sizes, and weighting of single foods of one FFQ item was carried out according to information obtained from the DONALD (Dortmund Nutritional and Anthropometric Longitudinally Designed) Study ${ }^{(17)}$ in order to represent the common consumption frequencies among the children's age group. This has been described in more detail by Stiegler et al. ${ }^{(14)}$. Missing categorical and continuous variables were replaced by median and mean frequencies of consumption, respectively, obtained from the remaining study population.

For food items rich in fat, such as butter, margarine, sausages and dairy products, additional questions on the fat content that subjects usually choose were asked and answers were applied to the relevant items on the list. Likewise, the energy content of beverages such as soft drinks and fruit drinks was considered.

Summation questions as introduced by Block et al. ${ }^{(18)}$ about the average consumption frequencies (per day or per week) of the food groups bread, fruit, vegetables and beverages were included at the end of the FFQ as general consumption frequencies have been assumed to be more valid than the sum of single frequencies ${ }^{(19)}$. They permit the adjustment of food consumption to reduce the overestimation resulting from the use of a long food item list while retaining the reported distribution of these foods. If the sum of the single food items was different from the overall estimate, individual correction factors were calculated by dividing the food group intake obtained by the summation question by the sum of intakes from the single food items belonging to this food group. Daily food intake was then multiplied by individual correction factors.

Questions on regular dietary vitamin and mineral supplement use were included at the end of the FFQ. The list of possible answers included 'multivitamins', 'vitamin C', 'vitamin E', 'vitamin B', ' $\beta$-carotene', 'Ca', 'Mg', 'fluorine' and 'others', allowing to specify other supplements regularly used by the participant. For the purpose of nutrient calculation, this information was linked to the supplement database of the DONALD Study, which contains detailed data on all supplement products ever recorded in the study's $3 \mathrm{~d}$ weighted dietary records ${ }^{(17)}$. However, as the contribution of vitamin intake by supplements was not significant and as we had only rough information about the dosage and frequency of supplement use, we abstained from including vitamin intake from supplements for our analyses. Fatty acid intake by supplementation such as fish oil could anyway not be considered because this was not recorded in the DONALD supplement database.

\section{Socio-economic status: parental education and bousebold income}

Parental education was determined on the basis of questionnaire-derived information about school education according to the German educational system, and was defined by the highest grade completed by either the mother or the father. Thus, children were assigned to the group of low (less than tenth grade), medium (tenth grade) or high (more than tenth grade) parental education.

Net household income per month was reported in the 10year questionnaire using a 9-point scale ranging from $<€ 500$ to $>€ 3500$. The calculation of equivalent income according to the OECD (Organisation for Economic Cooperation and Development) guidelines ${ }^{(20)}$ was carried out by dividing the net household income by an equivalence factor, which gives a weight of $1 \cdot 0$ to the first adult, 0.5 to all other adults and children $>14$ years, and 0.3 to all children up to 14 years. As income was measured categorically, we took the mid-point of each income class to calculate the income level. For the lowest income level $(<€ 500)$ we calculated two-thirds ( $€ 333$ ) of this limit, and for the highest income level (>€3500) four-thirds (€4667), as described before $^{(21)}$. Finally, the new variable was collapsed into three groups of low, medium and high household income. To enable comparing parental education with household income, a similar class size for both variables was needed. Therefore, the classification was based on quintiles so that the percentage of subjects in each group of household income equals the percentage of children in the respective 
group of parental education. Owing to the different income structure in the four study areas, classes were calculated separately for each study centre.

\section{Statistical analysis}

Nutrient and food intake data are presented by median and the 25 th and 75 th percentiles, stratified by region and gender. Food intake data are presented in $\mathrm{g} / \mathrm{d}$ (Table 2) and as mean contribution to total energy intake (Table 4). For all nutrients, intake data are given in $\mathrm{U} / \mathrm{MJ}$ and for macronutrients the percentage contribution to total daily energy intake (\%E) is also shown (Table 3). Statistically significant differences between study centres and gender in food and nutrient intake were tested by the nonparametric Kruskal-Wallis test.

Logistic regression modelling was used to analyse the effect of parental education, equivalent income and region on food intake adjusting for potential confounders. Food intake data were dichotomised and the upper $25 \%$ of intake for each gender- and centre-specific subgroup was used as outcome variable. Adjusted OR and the corresponding 95\% CI were computed. First, we examined the association between parental education and food intake adjusted for the covariates age and parental atopy. We then calculated a model that included equivalent income, age and parental atopy. Owing to the correlation between parental education and household income $(r=0 \cdot 28 ; P<0 \cdot 0001)$, mutual adjustment for these two influencing variables was not allowed. Furthermore, a model for the effect of living in Leipzig compared with Munich on food intake was analysed. For this purpose, gender-specific cut-off points for defining high food intake were used.

Supplement use is described as a percentage of the study population for boys and girls. In addition, logistic regression models were calculated to estimate the probability of regular supplement intake dependent on parental education and equivalent income, adjusted for gender, study centre and age. All computations were carried out using the statistical software R, version $2 \cdot 9 \cdot 1$ (R Foundation for Statistical Computing, Vienna, Austria) ${ }^{(22)}$.

\section{Results}

The study population consisted of 3435 children (1683 girls and 1752 boys) aged 9-12 years (median: 10·7). Altogether, $50 \cdot 3 \%$ and $7 \cdot 8 \%$ of all children lived in the urban areas of Munich (western Germany) and Leipzig (eastern Germany), respectively, whereas $37 \cdot 4 \%$ and $4.5 \%$ lived in the more rural areas of Wesel and Bad Honnef (both in western Germany). Table 1 shows the basic characteristics of the study population stratified for the four study centres. Children in Munich and Bad Honnef had a higher parental education than children in Leipzig and Wesel. Similarly, the highest equivalent income was reported in Munich, followed by Bad Honnef, Leipzig and Wesel. The mean body weight and height were $38 \cdot 0$ (SD $7 \cdot 5$ ) $\mathrm{kg}$ and $147 \cdot 8$ (SD $7 \cdot 4) \mathrm{cm}$, respectively. The median (50th percentile) BMI in the whole study population was $16 \cdot 8 \mathrm{~kg} / \mathrm{m}^{2}, 90 \%$ of all children showed a BMI $<20.7 \mathrm{~kg} / \mathrm{m}^{2}$ and $97 \%$ $<23 \cdot 2 \mathrm{~kg} / \mathrm{m}^{2}$. Minor differences in the distribution of these anthropometric measures among the study centres could be explained by age differences. An FFQ was mostly completed in autumn $(63.9 \%)$ compared with winter (15.5\%), spring $(13 \cdot 3 \%)$ and summer $(7 \cdot 3 \%)$.

The food group intakes in $\mathrm{g} / \mathrm{d}$ are presented in Table 2 according to study centre and gender. Children in Munich consumed less bread, margarine, dairy products and potatoes and more breakfast cereals (only boys), vegetable oil and fruit/vegetable juices than did children in the other study centres. The intakes of cheese, fruit, cake/ pastry and tea were highest in children from Leipzig, whereas they had the lowest intakes of rice, pizza and vegetables/salad compared with children from the other study centres. The highest intake for meat and the lowest intake for butter were observed in Wesel.

The median nutrient intakes per unit energy are presented in Table 3 according to study centre and gender. For boys, total energy intake was lowest in Munich, and for girls in Bad Honnef, whereas Wesel showed the highest energy intake for boys and Leipzig for girls. The macronutrient profiles, including energy derived from protein, carbohydrates and fat, were similar between the four study centres. Relying on $P$ values, statistically significant differences between the four study centres were observed for all nutrients, except vitamin C.

The two main sources of total daily energy intake were dairy products and bread, followed by meat products, breakfast cereals, pasta and fruit/vegetable juices (Table 4). The food groups with the smallest contribution to total energy intake $(<1 \%)$ were ice cream and fruit gums, eggs and nuts and seeds. The food group ranking in terms of $\% \mathrm{E}$ contribution was similar although not identical between boys and girls. Regional differences between the study centres were small and derived from the differences in daily food intake described in Table 2.

\section{Parental education, bousebold income, region and food intake}

The impact of parental education, equivalent income and regional effects on children's food intake was investigated by logistic regression models (Table 5), where the upper $25 \%$ of food intake for each gender- and centre-specific subgroup was the dependent variable. Food groups that showed a significant direct relationship with the level of parental education after adjusting for age and parental atopy were butter, eggs, vegetables/salad, fruit and vegetable oil. In turn, the intake of meat products, desserts, snacks and soft drinks was inversely associated with parental education.

In contrast, equivalent income showed a weaker influence on the child's food intake. Children with a comparatively high equivalent income had lower intakes 
Table 1 Basic characteristics of the study population: German children aged 9-12 years, GINIplus and LISAplus studies

\begin{tabular}{|c|c|c|c|c|c|c|c|c|c|c|}
\hline & \multicolumn{2}{|c|}{ Total ( $n$ 3435) } & \multicolumn{2}{|c|}{ Munich (n 1730) } & \multicolumn{2}{|c|}{ Leipzig ( $n$ 267) } & \multicolumn{2}{|c|}{ Wesel ( $n$ 1284) } & \multicolumn{2}{|c|}{ Bad Honnef $(n 154)$} \\
\hline & Mean & SD & Mean & SD & Mean & SD & Mean & SD & Mean & SD \\
\hline Boys (\%) & \multicolumn{2}{|c|}{$51 \cdot 0$} & \multicolumn{2}{|c|}{$51 \cdot 0$} & \multicolumn{2}{|c|}{$51 \cdot 7$} & \multirow{2}{*}{\multicolumn{2}{|c|}{$51 \cdot 2$}} & \multirow{2}{*}{\multicolumn{2}{|c|}{$48 \cdot 1$}} \\
\hline Age (years) & & & & & & & & & & \\
\hline Median & \multicolumn{2}{|c|}{$10 \cdot 72$} & \multirow{2}{*}{\multicolumn{2}{|c|}{$10 \cdot 7$}} & \multicolumn{2}{|c|}{$10 \cdot 3$} & \multicolumn{2}{|c|}{$11 \cdot 0$} & \multicolumn{2}{|c|}{$10 \cdot 6$} \\
\hline P5 & \multirow{2}{*}{\multicolumn{2}{|c|}{$\begin{array}{l}10 \cdot 13 \\
11.77\end{array}$}} & \multirow{2}{*}{\multicolumn{2}{|c|}{$\begin{array}{l}10 \cdot 2 \\
11 \cdot 7\end{array}$}} & \multicolumn{2}{|c|}{$9 \cdot 9$} & \multirow{2}{*}{\multicolumn{2}{|c|}{$\begin{array}{l}10 \cdot 3 \\
11 \cdot 8\end{array}$}} & \multicolumn{2}{|c|}{$10 \cdot 0$} \\
\hline P95 & & & & & \multicolumn{2}{|c|}{$10 \cdot 9$} & & & \multicolumn{2}{|c|}{$11 \cdot 1$} \\
\hline Level of parental & \multicolumn{2}{|c|}{$11 \cdot 77$} & & & & & & & & \\
\hline Low & \multicolumn{2}{|c|}{$5 \cdot 9$} & \multicolumn{2}{|c|}{$3 \cdot 5$} & \multicolumn{2}{|c|}{$1 \cdot 1$} & \multicolumn{2}{|c|}{$10 \cdot 5$} & \multicolumn{2}{|c|}{$3 \cdot 3$} \\
\hline Medium & \multicolumn{2}{|c|}{$26 \cdot 7$} & \multirow{2}{*}{\multicolumn{2}{|c|}{$\begin{array}{l}16 \cdot 9 \\
79 \cdot 6\end{array}$}} & \multicolumn{2}{|c|}{$39 \cdot 7$} & & & & \\
\hline High & 67 & & & & & & & & & \\
\hline Equivalent income & & & & & & & & & & \\
\hline Median & & & & & & & & & & \\
\hline P25 & & & & & & & & & & \\
\hline P75 & & & & & & & & & & \\
\hline Body height $(\mathrm{cm})$ & $147 \cdot 8$ & $7 \cdot 4$ & $147 \cdot 1$ & $7 \cdot 2$ & $144 \cdot 5$ & 7 & $149 \cdot 5$ & $7 \cdot 5$ & $146 \cdot 4$ & $6 \cdot 2$ \\
\hline Body weight $(\mathrm{kg})$ & 38 & $7 \cdot 5$ & $37 \cdot 2$ & 7 & $35 \cdot 6$ & $6 \cdot 4$ & $39 \cdot 6$ & $8 \cdot 2$ & $37 \cdot 6$ & $7 \cdot \overline{4}$ \\
\hline $\mathrm{BMI}\left(\mathrm{kg} / \mathrm{m}^{2}\right)$ & & & & & & & & & & \\
\hline P3 & & & & & & & & & & \\
\hline P50 (median) & & & & & & & & & & \\
\hline $\mathrm{P} 90$ & & & & & & & & & & \\
\hline P97 & & & & & & & & & & \\
\hline
\end{tabular}

$P 5$, 5th percentile; $P 95$, 95th percentile; $P 25$, 25th percentile; $P 75$, 75th percentile; $P 3$, 3rd percentile; $P 50,50$ th percentile; $P 90$, 90th percentile; $P 97$, 97th percentile.

of meat products and soft drinks and a higher pasta and fruit intake than those in the lowest income category. A model including age, parental atopy, parental education and equivalent income did not indicate that mutual adjustment would have any effect on the magnitude of OR (data not shown).

Table 5 also shows the effect estimates for the association between region (Leipzig, eastern Germany) compared with Munich (western Germany) and gender-specific high food intake controlling for parental education, age and parental atopy. Compared with Munich, children from Leipzig had statistically significant higher intakes of margarine, dairy products, eggs, potatoes, fruit, cake/ pastry, soft drinks and tea and lower intakes of breakfast cereals, pasta, rice, pizza and vegetable oil.

\section{Supplement use}

In total, the percentage of regular supplement users was 6.9 among boys and 6.6 among girls. About $9.2 \%$ of both sexes reported adding supplements irregularly to their diet (Table 6). Multivitamins were the most common supplements, used by $57 \cdot 0 \%$ (boys) and $50 \cdot 5 \%$ (girls) of all regular supplement users. Among the single vitamin or mineral products, vitamins $\mathrm{C}$ and $\mathrm{E}, \mathrm{Ca}$ and $\mathrm{Mg}$ were the most important ones. Fluorine was used by $9.0 \%$ of the boys and $17 \cdot 1 \%$ of the girls who were taking supplements regularly. A high proportion of children (28.9\% of all boys and $27 \cdot 0 \%$ of all girls) indicated taking dietary supplements other than the ones presented here. Due to the large variety of different supplements, they have been summarised into one heterogeneous group labelled 'other supplements'. The majority of supplement users $(5 \cdot 8 \%$ and $4 \cdot 8 \%)$ reported the use of only one type of supplement; $<2 \%$ took two or more.
Regular supplement use was more common among children in Munich (7.9\%) and Bad Honnef (8.4\%) than in Leipzig ( $4 \cdot 5 \%)$ and Wesel (5.5\%; data not shown). The proportion of supplement types varied between study centres, but because of the small numbers significance testing is limited. In Leipzig (66.7\%) and Bad Honnef $(69 \cdot 2 \%)$, the use of multivitamins was more often reported than in Munich (54.0\%) and Wesel (48.6\%; data not shown).

Supplement users were compared with non-users with respect to parental education and equivalent income in a multiple logistic regression model (Table 7). Neither parental education nor equivalent income showed a statistically significant relationship with regular supplement use in children, although more regular supplement users were found among children with medium (7·4\%) or high $(6 \cdot 8 \%)$ parental education compared with children with low parental education $(4 \cdot 7 \%)$.

\section{Discussion}

The results of the present study suggest an association of parental education and region with food intake in 9-12year-old children, whereas association with the level of equivalent income was weak. No statistically significant associations were observed between parental education or equivalent income and supplement intake in children.

The descriptive food and nutrient intake data of the present study were partly in very good agreement with data from the nationally representative eating study (EsKiMo) $^{(23)}$ as part of the KiGGS study. The absolute intakes (in $\mathrm{g} / \mathrm{d}$ ) for 10-11-year-old boys in the EsKiMo study and for 9-12-year-old boys in the present study 
Table 2 Median intake of food groups per day in the study population by gender and region

\begin{tabular}{|c|c|c|c|c|c|c|c|c|c|c|c|c|c|c|c|c|c|}
\hline \multirow[b]{2}{*}{ Food group (g/d) } & \multirow[b]{2}{*}{ Gender } & \multicolumn{3}{|c|}{ Total (n 3435) } & \multicolumn{3}{|c|}{ Munich ( $n$ 1730) } & \multicolumn{3}{|c|}{ Leipzig (n 267) } & \multicolumn{3}{|c|}{ Wesel ( $n$ 1284) } & \multicolumn{3}{|c|}{ Bad Honnef ( $n$ 154) } & \multirow[b]{2}{*}{$P$ value* } \\
\hline & & Mean & P25 & P75 & Mean & P25 & P75 & Mean & P25 & P75 & Mean & P25 & P75 & Mean & P25 & P75 & \\
\hline \multirow[t]{2}{*}{ Bread } & Boys & 115 & 82 & 158 & 104 & 77 & 146 & 124 & 93 & 180 & 134 & 92 & 216 & 124 & 92 & 205 & $<0.0001$ \\
\hline & Girls & 103 & 76 & 141 & 98 & 72 & 137 & 127 & 96 & 170 & 118 & 76 & 176 & 125 & 82 & 162 & $<0.0001$ \\
\hline \multirow[t]{2}{*}{ Butter } & Boys & 2 & 0 & 8 & 4 & 1 & 10 & 2 & 1 & 6 & 0 & 0 & 3 & 3 & 0 & 9 & $<0.0001$ \\
\hline & Girls & 2 & 0 & 6 & 4 & 1 & 10 & 4 & 1 & 10 & 0 & 0 & 2 & 2 & 0 & 5 & $<0.0001$ \\
\hline \multirow[t]{2}{*}{ Margarine } & Boys & 1 & 0 & 5 & 0 & 0 & 2 & 3 & 0 & 9 & 4 & 1 & 10 & 1 & 0 & 4 & $<0.0001$ \\
\hline & Girls & 1 & 0 & 5 & 0 & 0 & 1 & 3 & 0 & 10 & 3 & 1 & 9 & 3 & 1 & 6 & $<0.0001$ \\
\hline \multirow[t]{2}{*}{ Cheese } & Boys & 15 & 6 & 35 & 17 & 7 & 36 & 21 & 8 & 38 & 13 & 4 & 33 & 12 & 4 & 23 & $<0.0001$ \\
\hline & Girls & 16 & 6 & 33 & 17 & 7 & 34 & 23 & 12 & 40 & 13 & 5 & 29 & 22 & 8 & 40 & $<0.0001$ \\
\hline \multirow[t]{2}{*}{ Meat } & Boys & 52 & 33 & 81 & 45 & 30 & 70 & 46 & 33 & 70 & 64 & 43 & 91 & 47 & 32 & 79 & $<0.0001$ \\
\hline & Girls & 43 & 28 & 64 & 35 & 24 & 55 & 44 & 28 & 61 & 54 & 35 & 79 & 45 & 32 & 65 & $<0.0001$ \\
\hline Meat products & Boys & 49 & 29 & 75 & 47 & 29 & 73 & 49 & 30 & 73 & 51 & 30 & 82 & 46 & 27 & 74 & 0.0492 \\
\hline & Girls & 38 & 22 & 59 & 38 & 20 & 57 & 44 & 26 & 60 & 38 & 22 & 63 & 33 & 25 & 52 & 0.0841 \\
\hline Breakfast cereals & Boys & 25 & 8 & 54 & 36 & 11 & 54 & 27 & 9 & 50 & 18 & 7 & 49 & 19 & 9 & 51 & $<0.0001$ \\
\hline & Girls & 19 & 7 & 40 & 21 & 8 & 50 & 20 & 8 & 36 & 18 & 6 & 37 & 22 & 7 & 43 & 0.0074 \\
\hline Dairy products & Boys & 341 & 210 & 580 & 294 & 190 & 464 & 358 & 219 & 571 & 449 & 243 & 740 & 335 & 175 & 577 & $<0.0001$ \\
\hline & Girls & 263 & 153 & 427 & 246 & 134 & 369 & 302 & 176 & 471 & 307 & 166 & 521 & 272 & 147 & 397 & $<0.0001$ \\
\hline Eggs & Boys & 8 & 5 & 16 & 8 & 5 & 16 & 8 & 8 & 16 & 8 & 5 & 16 & 8 & 5 & 19 & 0.0150 \\
\hline & Girls & 8 & 5 & 9 & 8 & 5 & 8 & 8 & 5 & 14 & 8 & 5 & 10 & 8 & 5 & 8 & 0.5300 \\
\hline Potatoes & Boys & 51 & 29 & 83 & 38 & 23 & 65 & 64 & 41 & 87 & 73 & 46 & 110 & 65 & 43 & 83 & $<0.0001$ \\
\hline & Girls & 46 & 28 & 73 & 32 & 21 & 63 & 52 & 41 & 77 & 63 & 43 & 98 & 63 & 37 & 83 & $<0.0001$ \\
\hline Pasta & Boys & 38 & 18 & 61 & 38 & 24 & 61 & 38 & 18 & 38 & 38 & 15 & 38 & 38 & 18 & 55 & $<0.0001$ \\
\hline & Girls & 38 & 18 & 61 & 38 & 24 & 61 & 38 & 15 & 38 & 38 & 15 & 38 & 38 & 18 & 61 & $<0.0001$ \\
\hline Rice & Boys & 13 & 7 & 19 & 13 & 7 & 22 & 8 & 7 & 13 & 13 & 7 & 18 & 10 & 6 & 13 & 0.0123 \\
\hline & Girls & 13 & 7 & 13 & 13 & 7 & 18 & 8 & 4 & 13 & 13 & 7 & 13 & 13 & 7 & 13 & 0.0060 \\
\hline Pizza & Boys & 28 & 13 & 33 & 28 & 16 & 47 & 13 & 11 & 28 & 28 & 13 & 33 & 28 & 11 & 33 & $<0.0001$ \\
\hline & Girls & 28 & 11 & 28 & 28 & 13 & 33 & 11 & 6 & 28 & 28 & 11 & 28 & 28 & 11 & 28 & $<0.0001$ \\
\hline Fish & Boys & 17 & 10 & 28 & 17 & 10 & 28 & 19 & 11 & 28 & 17 & 10 & 28 & 18 & 10 & 31 & $0 \cdot 2765$ \\
\hline & Girls & 14 & 7 & 24 & 16 & 7 & 25 & 17 & 10 & 26 & 12 & 7 & 22 & 12 & 7 & 23 & 0.0214 \\
\hline Vegetables & Boys & 104 & 65 & 157 & 111 & 69 & 167 & 54 & 24 & 91 & 100 & 62 & 145 & 119 & 79 & 171 & $<0.0001$ \\
\hline and salad & Girls & 115 & 72 & 171 & 123 & 78 & 177 & 54 & 34 & 102 & 106 & 70 & 160 & 109 & 63 & 161 & $<0.0001$ \\
\hline Fruit & Boys & 110 & 66 & 159 & 110 & 65 & 156 & 131 & 77 & 232 & 108 & 66 & 154 & 110 & 69 & 161 & $<0.0001$ \\
\hline & Girls & 114 & 79 & 162 & 115 & 83 & 162 & 137 & 93 & 234 & 111 & 67 & 157 & 113 & 67 & 156 & $<0.0001$ \\
\hline Cake and pastry & Boys & 24 & 15 & 38 & 23 & 15 & 37 & 30 & 19 & 49 & 24 & 15 & 38 & 22 & 13 & 34 & 0.0005 \\
\hline & Girls & 23 & 15 & 37 & 23 & 14 & 35 & 28 & 19 & 53 & 23 & 15 & 38 & 23 & 15 & 32 & 0.0010 \\
\hline Desserts & Boys & 10 & 3 & 18 & 10 & 3 & 17 & 10 & 8 & 18 & 10 & 4 & 18 & 8 & 3 & 18 & $<0.0001$ \\
\hline & Girls & 8 & 3 & 14 & 8 & 3 & 14 & 8 & 4 & 14 & 8 & 3 & 16 & 8 & 4 & 14 & 0.0296 \\
\hline Chocolate & Boys & 11 & 6 & 23 & 10 & 5 & 23 & 12 & 7 & 19 & 12 & 7 & 23 & 10 & 4 & 23 & 0.0653 \\
\hline & Girls & 10 & 5 & 19 & 9 & 4 & 18 & 9 & 5 & 19 & 10 & 5 & 19 & 10 & 6 & 18 & 0.0871 \\
\hline Ice cream and & Boys & 7 & 4 & 12 & 7 & 4 & 12 & 7 & 3 & 16 & 7 & 4 & 12 & 8 & 4 & 15 & 0.5502 \\
\hline fruit gums & Girls & 6 & 4 & 11 & 6 & 3 & 11 & 8 & 4 & 14 & 6 & 4 & 11 & 7 & 4 & 12 & $0 \cdot 1968$ \\
\hline Snacks & Boys & 4 & 1 & 7 & 2 & 1 & 4 & 4 & 2 & 6 & 4 & 2 & 7 & 2 & 1 & 7 & $<0.0001$ \\
\hline & Girls & 2 & 1 & 6 & 2 & 1 & 4 & 2 & 1 & 4 & 4 & 2 & 7 & 2 & 1 & 4 & $<0.0001$ \\
\hline Nuts and seeds & Boys & 1 & 0 & 3 & 1 & 0 & 3 & 1 & 0 & 2 & 1 & 0 & 2 & 1 & 0 & 3 & 0.4357 \\
\hline & Girls & 1 & 0 & 2 & 1 & 0 & 2 & 1 & 0 & 2 & 1 & 0 & 2 & 1 & 0 & 4 & 0.0670 \\
\hline Vegetable oil & Boys & 2 & 1 & 5 & 3 & 2 & 6 & 1 & 1 & 2 & 2 & 1 & 4 & 2 & 1 & 4 & $<0.0001$ \\
\hline & Girls & 2 & 1 & 4 & 3 & 2 & 5 & 1 & 1 & 3 & 2 & 1 & 3 & 2 & 1 & 5 & $<0.0001$ \\
\hline Fruit/vegetable & Boys & 368 & 132 & 714 & 429 & 145 & 744 & 313 & 133 & 665 & 328 & 124 & 683 & 248 & 85 & 624 & 0.0184 \\
\hline juice & Girls & 331 & 115 & 630 & 367 & 120 & 656 & 363 & 128 & 640 & 283 & 99 & 584 & 313 & 114 & 623 & 0.0478 \\
\hline Soft drinks & Boys & 34 & 13 & 120 & 31 & 12 & 94 & 36 & 10 & 132 & 42 & 15 & 162 & 30 & 10 & 83 & 0.0008 \\
\hline & Girls & 22 & 8 & 65 & 18 & 7 & 48 & 27 & 8 & 78 & 28 & 10 & 94 & 24 & 7 & 98 & $<0.0001$ \\
\hline Tea & Boys & 15 & 0 & 79 & 25 & 5 & 104 & 76 & 22 & 276 & 4 & 0 & 25 & 13 & 2 & 53 & $<0.0001$ \\
\hline & Girls & 24 & 4 & 99 & 34 & 7 & 123 & 90 & 24 & 249 & 11 & 0 & 51 & 21 & 0 & 104 & $<0.0001$ \\
\hline
\end{tabular}

P25, 25th percentile; P75, 75th percentile.

${ }^{*}$ Kruskal-Wallis test.

were very similar for the food groups bread (105 $\mathrm{g}$ and $115 \mathrm{~g}$ ), cheese (17 $\mathrm{g}$ and $15 \mathrm{~g}$ ), eggs ( $9 \mathrm{~g}$ and $8 \mathrm{~g}$ ), potatoes $(53 \mathrm{~g}$ and $51 \mathrm{~g})$, pasta $(37 \mathrm{~g}$ and $38 \mathrm{~g}$ ) and fruit (112 $\mathrm{g}$ and $110 \mathrm{~g})$. In contrast, the reported intakes of meat $(52 \mathrm{~g}$ and $25 \mathrm{~g}$ ), breakfast cereals ( $25 \mathrm{~g}$ and $9 \mathrm{~g}$ ), dairy products $(341 \mathrm{~g}$ and $244 \mathrm{~g})$ and fruit/vegetable juice $(368 \mathrm{~g}$ and $193 \mathrm{~g}$ ) derived from our FFQ were much higher than the corresponding EsKiMo intake data and may have even overestimated the true intakes. However, absolute intake data are in general hardly comparable because of different food group definitions and aggregation levels. In any case, the main sources of total daily energy intake in our study population were comparable to those reported by the EsKiMo study. Dairy products $(15.5 \%$ and $11 \%$ ), bread (13.8\% and $14 \%)$, fruit/vegetable juices $(5.7 \%$ and $7 \%)$ and cake/pastry ( $5.0 \%$ and $7 \%)$ were ranked among the first eight food groups in both studies, where the first value given in brackets corresponds to all boys of the 
Table 3 Median nutrient intakes per unit energy in the study population by gender and region

\begin{tabular}{|c|c|c|c|c|c|c|c|c|c|c|c|c|c|c|c|c|c|}
\hline \multirow[b]{2}{*}{ Nutrient } & \multirow[b]{2}{*}{ Gender } & \multicolumn{3}{|c|}{ Total ( $n$ 3435) } & \multicolumn{3}{|c|}{ Munich ( $n$ 1730) } & \multicolumn{3}{|c|}{ Leipzig ( $n$ 267) } & \multicolumn{3}{|c|}{ Wesel $(n$ 1284) } & \multicolumn{3}{|c|}{ Bad Honnef ( $n$ 154) } & \multirow[b]{2}{*}{$P$ value $^{*}$} \\
\hline & & Mean & P25 & P75 & Mean & P25 & P75 & Mean & P25 & P75 & Mean & P25 & P75 & Mean & P25 & P75 & \\
\hline \multirow[t]{2}{*}{ Energy (kJ) } & Boys & 8971 & 7349 & 11016 & 8658 & 7077 & 10499 & 8855 & 7388 & 10991 & 9472 & 7707 & 11681 & 8947 & 7226 & 10908 & 0.0000 \\
\hline & Girls & 7708 & 6295 & 9352 & 7604 & 6250 & 8991 & 8261 & 6519 & 9948 & 7854 & 6334 & 9698 & 7432 & 6261 & 9557 & 0.0033 \\
\hline \multirow[t]{2}{*}{ Energy (kcal) } & Boys & 2143 & 1756 & 2631 & 2069 & 1691 & 2508 & 2116 & 1765 & 2626 & 2262 & 1841 & 2791 & 2139 & 1727 & 2606 & $<0.0001$ \\
\hline & Girls & 1840 & 1503 & 2234 & 1816 & 1493 & 2147 & 1973 & 1557 & 2373 & 1874 & 1512 & 2316 & 1775 & 1496 & 2281 & 0.0034 \\
\hline \multirow{2}{*}{ Protein (\%E) } & Boys & 14 & 11 & 18 & 14 & 12 & 18 & 14 & 12 & 17 & 15 & 11 & 19 & 14 & 12 & 18 & $<0.0001$ \\
\hline & Girls & 14 & 11 & 18 & 14 & 11 & 17 & 14 & 11 & 17 & 15 & 12 & 19 & 15 & 12 & 20 & $<0.0001$ \\
\hline \multirow[t]{2}{*}{ Carbohydrates (\%E) } & Boys & 54 & 44 & 67 & 55 & 44 & 67 & 56 & 45 & 68 & 54 & 43 & 67 & 57 & 42 & 65 & $<0.0001$ \\
\hline & Girls & 55 & 44 & 68 & 54 & 44 & 66 & 54 & 42 & 68 & 54 & 44 & 68 & 58 & 46 & 72 & 0.0093 \\
\hline \multirow[t]{2}{*}{ Total fat (\%E) } & Boys & 29 & 22 & 37 & 29 & 23 & 37 & 28 & 22 & 36 & 29 & 23 & 38 & 29 & 21 & 37 & $<0.0001$ \\
\hline & Girls & 29 & 22 & 36 & 29 & 22 & 36 & 29 & 23 & 36 & 28 & 23 & 36 & 29 & 24 & 40 & 0.0406 \\
\hline \multirow{2}{*}{ SFA (mg/MJ) } & Boys & 3237 & 2433 & 4268 & 3212 & 2445 & 4170 & 3265 & 2494 & 4114 & 3264 & 2457 & 4359 & 3123 & 2228 & 4499 & 0.0000 \\
\hline & Girls & 3163 & 2425 & 4080 & 3138 & 2388 & 4098 & 3324 & 2536 & 4015 & 3146 & 2401 & 3955 & 3237 & 2493 & 4316 & 0.0202 \\
\hline \multirow[t]{2}{*}{ MUFA (mg/MJ) } & Boys & 2707 & 2068 & 3519 & 2754 & 2094 & 3587 & 2617 & 2190 & 3239 & 2707 & 2049 & 3582 & 2767 & 2024 & 3323 & 0.0013 \\
\hline & Girls & 2645 & 2025 & 3391 & 2634 & 2016 & 3409 & 2663 & 2087 & 3232 & 2600 & 2021 & 3374 & 2679 & 2149 & 3374 & 0.1191 \\
\hline \multirow{2}{*}{ PUFA (mg/MJ) } & Boys & 1130 & 866 & 1458 & 1126 & 863 & 1455 & 1073 & 861 & 1268 & 1150 & 889 & 1440 & 1065 & 865 & 1387 & $<0.0001$ \\
\hline & Girls & 1140 & 882 & 1439 & 1106 & 848 & 1391 & 1048 & 813 & 1327 & 1183 & 904 & 1492 & 1172 & 985 & 1516 & $<0.0001$ \\
\hline \multirow[t]{2}{*}{ Linoleic acid ( $n-6 ; \mathrm{mg} / \mathrm{MJ})$} & Boys & 955 & 729 & 1233 & 959 & 726 & 1235 & 908 & 707 & 1085 & 974 & 744 & 1249 & 905 & 705 & 1165 & $<0.0001$ \\
\hline & Girls & 960 & 741 & 1230 & 939 & 714 & 1185 & 872 & 679 & 1097 & 1005 & 766 & 1287 & 981 & 834 & 1267 & $<0.0001$ \\
\hline \multirow[t]{2}{*}{ Arachidonic acid (n-6; mg/MJ) } & Boys & 21 & 15 & 28 & 20 & 14 & 27 & 19 & 14 & 24 & 22 & 16 & 31 & 21 & 16 & 31 & $<0.0001$ \\
\hline & Girls & 20 & 15 & 28 & 19 & 13 & 26 & 19 & 13 & 24 & 22 & 17 & 32 & 22 & 17 & 30 & $<0.0001$ \\
\hline \multirow[t]{2}{*}{ EPA $(n-3 ; \mu \mathrm{g} / \mathrm{MJ})$} & Boys & 3767 & 2038 & 6845 & 3713 & 2014 & 6895 & 4454 & 2674 & 8068 & 3603 & 2054 & 6431 & 3817 & 1909 & 7358 & 0.0284 \\
\hline & Girls & 3498 & 1898 & 6904 & 3695 & 1946 & 7487 & 4124 & 2210 & 8338 & 3301 & 1782 & 5802 & 3052 & 1913 & 6730 & 0.0151 \\
\hline \multirow[t]{2}{*}{ DPA $(n-3 ; \mu \mathrm{g} / \mathrm{MJ})$} & Boys & 1262 & 720 & 2010 & 1195 & 676 & 1939 & 1491 & 827 & 2127 & 1259 & 741 & 2076 & 1303 & 766 & 1853 & 0.0022 \\
\hline & Girls & 1212 & 691 & 2068 & 1199 & 660 & 2058 & 1373 & 797 & 2352 & 1218 & 703 & 1993 & 1068 & 727 & 2236 & 0.1037 \\
\hline \multirow[t]{2}{*}{ Vitamin $A(\mu \mathrm{g} / \mathrm{MJ})$} & Boys & 114 & 75 & 172 & 117 & 77 & 176 & 117 & 77 & 178 & 108 & 72 & 166 & 122 & 88 & 171 & 0.6453 \\
\hline & Girls & 121 & 86 & 183 & 128 & 89 & 188 & 117 & 82 & 195 & 112 & 82 & 169 & 126 & 89 & 203 & 0.0098 \\
\hline \multirow[t]{2}{*}{ Vitamin $E(\mu \mathrm{g} / \mathrm{MJ})$} & Boys & 999 & 781 & 1311 & 1042 & 802 & 1374 & 942 & 724 & 1205 & 959 & 763 & 1259 & 961 & 835 & 1207 & 0.0166 \\
\hline & Girls & 1077 & 835 & 1382 & 1092 & 850 & 1408 & 1007 & 751 & 1211 & 1053 & 820 & 1352 & 1183 & 904 & 1488 & 0.3731 \\
\hline \multirow[t]{2}{*}{ Vitamin C (mg/MJ) } & Boys & 10 & 7 & 14 & 10 & 7 & 14 & 10 & 6 & 14 & 10 & 7 & 13 & 10 & 7 & 14 & 0.2121 \\
\hline & Girls & 11 & 8 & 15 & 11 & 8 & 15 & 10 & 8 & 15 & 11 & 8 & 16 & 12 & 8 & 16 & 0.9318 \\
\hline
\end{tabular}

P25, 25th percentile; P75, 75th percentile.

*Kruskal-Wallis test. 
Table 4 Mean contribution of food groups to total energy intake in boys and girls

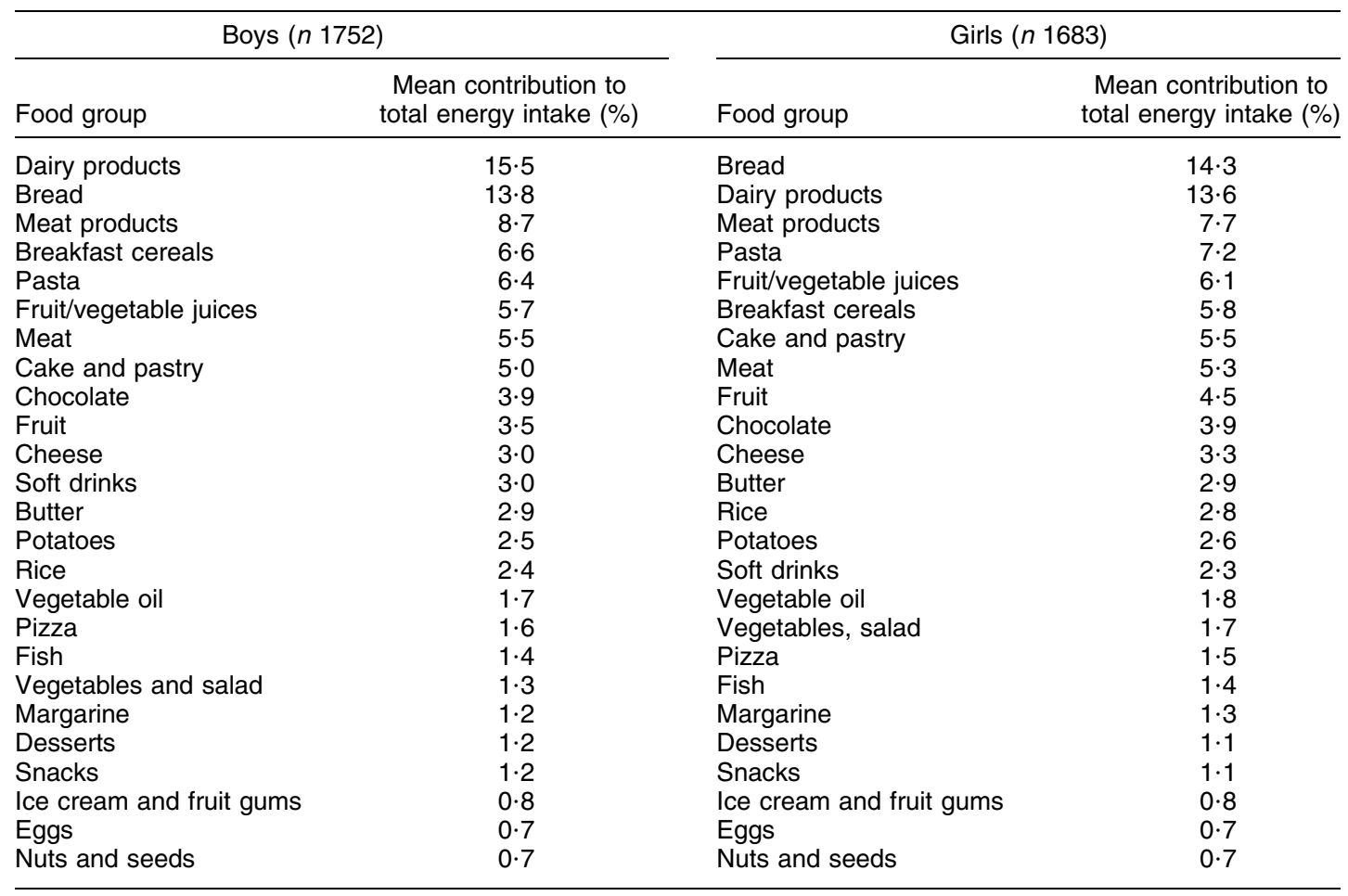

present study population and the second value to 6-11year-old boys of the EsKiMo study. This general good agreement was also reflected on the nutrient level, as intakes of the macronutrients fat, protein and carbohydrates as well as vitamins $\mathrm{E}$ and $\mathrm{C}$ corresponded to the values reported by the EsKiMo study. Only total energy intake in boys ( $8971 \mathrm{~kJ}(2143 \mathrm{kcal})$ and $7586 \mathrm{~kJ}(1813 \mathrm{kcal}))$ seemed to be overestimated in the present study.

For children, the KiGGS study suggests no persisting dietary differences in intakes between children from eastern and western Germany ${ }^{(24)}$, which is in contrast to our findings. We compared food group intakes between metropolitan areas such as Leipzig in the east and Munich in the west of Germany and observed some significant differences for the food groups margarine, dairy products, eggs, potatoes, fruit, cake/pastry, soft drinks, tea, breakfast cereals, pasta, rice, pizza and vegetable oil. The study centres Wesel and Bad Honnef have been excluded from the analysis although they are located in the west of Germany. Owing to the heterogeneity of the three western study centres, rural/urban and north/west differences would be implied in the east/west comparison. Certainly, the different socio-economic structures of the two study centres might have contributed to the observed regional effects as, for example, parents in Munich (79.6\%) more likely had a high educational level than in Leipzig $(59 \cdot 2 \%$; see Table 1$)$. Thus, the correlation between parental education and region $(r=0 \cdot 17 ; P<0 \cdot 0001)$ might have led to residual confounding even after controlling for parental education. As this could also affect the association between parental education and food intake, we calculated gender- and centre-specific cut-off points for defining high food intake for analysing the association with parental education to minimise the described effect.

Comparing present findings with other studies is difficult because various measures for socio-economic position have been used, including education, income or occupation, which have been shown not to serve as adequate proxies for one another ${ }^{(25)}$. According to the findings of the present study, the intakes of butter, eggs, vegetables/ salad, fruit, vegetable oil, meat products, desserts, snacks and soft drinks in children varied by level of parental education. Our findings are thus in line with probably the most consistent evidence of dietary inequalities in adults, showing a lower consumption of fruit and vegetables among socio-economically disadvantaged groups ${ }^{(4)}$. This has also been reported by a study carried out in German schoolchildren, a part of WHO's cross-sectional survey HBSC (Health Behaviour in School-Aged Children) ${ }^{(26)}$, showing that the impact of the social situation was particularly strong for healthy foods, such as raw vegetables, fruit and wholegrain wheat bread. A Finnish study in children aged 9-15 years also reported that children of families with higher socio-economic status used more fruit than did children of families with lower socio-economic status, where family's socio-economic status was defined according to the father's educational level, his occupation and family income ${ }^{(27)}$. Contrary to our findings, they reported that high socio-economic status was associated with a higher margarine intake, whereas children of low 
Table 5 Results of logistic regression models of parental education, equivalent income and region on children's food intake (defined as the upper $25 \%$ of each gender- and center-specific subgroups)

\begin{tabular}{|c|c|c|c|c|c|c|c|c|c|c|}
\hline \multirow[b]{3}{*}{ Food group (g/d) } & \multicolumn{4}{|c|}{ Parental education } & \multicolumn{4}{|c|}{ Equivalent income } & \multirow{2}{*}{\multicolumn{2}{|c|}{$\begin{array}{c}\text { Region } \\
\text { Leipzig } v \text {. Munich }(n \text { 267) }\end{array}$}} \\
\hline & \multicolumn{2}{|c|}{ Medium $v$. low ( $n$ 888) } & \multicolumn{2}{|c|}{ High v. low (n 2236) } & \multicolumn{2}{|c|}{ Medium v. low ( $n$ 699) } & \multicolumn{2}{|c|}{ High $v$. low ( $n$ 2401) } & & \\
\hline & $\mathrm{aOR}^{*}$ & $95 \% \mathrm{Cl}$ & $\mathrm{aOR}^{*}$ & $95 \% \mathrm{Cl}$ & $\mathrm{aOR}^{\star}$ & $95 \% \mathrm{Cl}$ & $\mathrm{aOR}^{*}$ & $95 \% \mathrm{Cl}$ & aORt & $95 \% \mathrm{Cl}$ \\
\hline Bread & 0.89 & $0 \cdot 61,1 \cdot 29$ & $1 \cdot 16$ & $0.82,1 \cdot 65$ & 0.68 & $0.48,0.95$ & 0.90 & $0 \cdot 66,1 \cdot 22$ & 1.05 & $0 \cdot 75,1 \cdot 48$ \\
\hline Butter & $1 \cdot 11$ & $0.73,1.67$ & 1.88 & $1 \cdot 28,2 \cdot 78$ & 1.06 & $0.74,1.54$ & $1 \cdot 37$ & $0.98,1.92$ & 0.99 & $0.70,1.40$ \\
\hline Margarine & 1.09 & $0.77,1.54$ & 0.79 & $0.57,1.09$ & 0.95 & $0 \cdot 68,1 \cdot 32$ & 0.79 & $0.58,1.07$ & $3 \cdot 89$ & $2 \cdot 85,5 \cdot 32$ \\
\hline Cheese & 0.95 & $0.66,1.37$ & $1 \cdot 12$ & $0.80,1.58$ & 0.76 & $0.54,1.05$ & 0.79 & $0.58,1.06$ & $1 \cdot 19$ & $0.85,1.65$ \\
\hline Meat & $1 \cdot 10$ & $0.78,1.57$ & 0.81 & $0.58,1.14$ & $1 \cdot 04$ & $0.74,1.46$ & 0.95 & $0 \cdot 70,1 \cdot 30$ & $1 \cdot 15$ & $0.82,1.60$ \\
\hline Meat products & 0.78 & $0.55,1 \cdot 10$ & 0.64 & $0.46,0.88$ & 0.82 & $0 \cdot 59,1 \cdot 14$ & 0.68 & $0.50,0.92$ & 1.03 & $0 \cdot 74,1 \cdot 44$ \\
\hline Breakfast cereals & $1 \cdot 34$ & $0.91,1.96$ & 1.43 & $0.99,2.07$ & 0.84 & $0 \cdot 60,1 \cdot 17$ & 0.87 & $0.64,1 \cdot 18$ & 0.64 & $0.45,0.92$ \\
\hline Dairy products & 1.06 & $0.74,1.50$ & 0.85 & $0.61,1 \cdot 18$ & 0.82 & $0 \cdot 59,1 \cdot 14$ & 0.78 & $0.58,1.05$ & $1 \cdot 81$ & $1 \cdot 31,2 \cdot 48$ \\
\hline Eggs & $1 \cdot 39$ & $0.94,2.04$ & 1.45 & $1 \cdot 01,2 \cdot 09$ & $1 \cdot 17$ & $0.83,1.65$ & 1.02 & $0.74,1.39$ & $1 \cdot 39$ & $1.00,1.92$ \\
\hline Potatoes & 0.92 & $0.65,1.31$ & 0.89 & $0 \cdot 64,1 \cdot 25$ & 0.87 & $0 \cdot 63,1 \cdot 21$ & 0.74 & $0.55,1.00$ & $2 \cdot 23$ & $1.63,3.05$ \\
\hline $\begin{array}{l}\text { Pasta } \\
\end{array}$ & 1.09 & $0.79,1.50$ & $1 \cdot 25$ & $0.92,1.69$ & $1 \cdot 07$ & $0.78,1.46$ & $1 \cdot 36$ & $1 \cdot 02,1 \cdot 81$ & 0.42 & $0.29,0.59$ \\
\hline Rice & $1 \cdot 11$ & $0.80,1.56$ & 1.09 & $0 \cdot 80,1 \cdot 50$ & $1 \cdot 23$ & $0 \cdot 88,1 \cdot 72$ & $1 \cdot 25$ & $0.92,1 \cdot 70$ & $0 \cdot 60$ & $0.43,0.83$ \\
\hline Pizza & 0.85 & $0.61,1 \cdot 17$ & 0.77 & $0.57,1.05$ & 1.05 & $0.76,1.45$ & 0.99 & $0.74,1.33$ & 0.27 & $0 \cdot 18,0.41$ \\
\hline Fish & 0.83 & $0.58,1.18$ & 0.85 & $0 \cdot 61,1 \cdot 19$ & $1 \cdot 00$ & $0.71,1 \cdot 40$ & 0.93 & $0.68,1.27$ & 1.08 & $0.77,1.50$ \\
\hline Vegetables and salad & 1.43 & $0.95,2 \cdot 14$ & $1 \cdot 70$ & $1 \cdot 16,2 \cdot 51$ & 1.07 & $0.75,1.52$ & $1 \cdot 08$ & $0.78,1.49$ & 0.73 & $0.51,1.05$ \\
\hline Fruit & 1.99 & $1 \cdot 27,3 \cdot 10$ & $2 \cdot 44$ & $1 \cdot 60,3 \cdot 74$ & $1 \cdot 16$ & $0.80,1.68$ & $1 \cdot 44$ & $1 \cdot 03,2 \cdot 02$ & $2 \cdot 32$ & $1 \cdot 69,3 \cdot 18$ \\
\hline Cake and pastry & $1 \cdot 16$ & $0.80,1.68$ & $1 \cdot 10$ & $0.77,1.56$ & 0.85 & $0 \cdot 61,1 \cdot 19$ & 0.78 & $0.58,1.06$ & 1.94 & $1.42,2.66$ \\
\hline Desserts & 0.66 & $0.48,0.91$ & 0.53 & $0.39,0.73$ & 0.88 & $0.64,1.22$ & 0.89 & $0.66,1 \cdot 19$ & $1 \cdot 15$ & $0.84,1.58$ \\
\hline Chocolate & $0 \cdot 88$ & $0.63,1.24$ & 0.73 & $0.53,1.01$ & $1 \cdot 00$ & $0 \cdot 71,1 \cdot 41$ & 0.95 & $0 \cdot 70,1 \cdot 29$ & 0.86 & $0.61,1.21$ \\
\hline Ice cream and fruit gums & $1 \cdot 01$ & $0.71,1.43$ & 0.83 & $0 \cdot 60,1 \cdot 17$ & $1 \cdot 17$ & $0.84,1 \cdot 64$ & 0.86 & $0.63,1 \cdot 17$ & $1 \cdot 18$ & $0.85,1.63$ \\
\hline Snacks & 1.07 & $0 \cdot 78,1 \cdot 48$ & 0.73 & $0.54,0.99$ & 0.95 & $0 \cdot 70,1 \cdot 29$ & $0 \cdot 77$ & $0.58,1.03$ & $1 \cdot 19$ & $0.88,1.62$ \\
\hline Nuts and seeds & $1 \cdot 14$ & $0.79,1.64$ & $1 \cdot 14$ & $0 \cdot 81,1 \cdot 61$ & 1.04 & $0 \cdot 74,1 \cdot 45$ & $0 \cdot 88$ & $0 \cdot 65,1 \cdot 19$ & 0.78 & $0.55,1.11$ \\
\hline Vegetable oil & $1 \cdot 28$ & $0.86,1.92$ & 1.68 & $1 \cdot 15,2 \cdot 45$ & $1 \cdot 24$ & $0 \cdot 86,1 \cdot 80$ & 1.37 & $0.98,1.92$ & $0 \cdot 20$ & $0.12,0.34$ \\
\hline Fruit/vegetable juice & 1.06 & $0.74,1.52$ & $1 \cdot 00$ & $0.71,1.40$ & $1 \cdot 25$ & $0 \cdot 87,1 \cdot 78$ & $1 \cdot 16$ & $0.84,1.61$ & 0.84 & $0 \cdot 60,1 \cdot 19$ \\
\hline Soft drinks & 0.67 & $0.49,0.93$ & 0.44 & $0.32,0.59$ & 0.81 & $0.59,1 \cdot 12$ & 0.63 & $0.47,0.84$ & $1 \cdot 44$ & $1 \cdot 04,2 \cdot 00$ \\
\hline Tea & 1.03 & $0.71,1.49$ & $1 \cdot 14$ & $0 \cdot 80,1 \cdot 61$ & $0 \cdot 78$ & $0.55,1.09$ & 0.82 & $0 \cdot 60,1 \cdot 10$ & 2.55 & $1 \cdot 86,3.49$ \\
\hline
\end{tabular}

\section{$\mathrm{OR}$, adjusted $\mathrm{OR}$}

Low parental education, low family income and the study centre in Munich formed the reference category.

$25 \%$ ).

OR adjusted for parental education, age and parental atopy; gender-specific cut-off points were used to define high intake (upper $25 \%$ ) 
socio-economic status had a higher intake of butter. However, although the parental education level was lower in Leipzig compared with Munich, fruit intake was higher in this eastern German city. This result strongly points to the additional impact of further influencing factors on food intake.

Another study showed that among several potential predictors of fruit and vegetable consumption analysed in pre-school children, maternal education emerged to be positively associated with children's vegetable consumption whereas no effect of fruit intake was reported ${ }^{(28)}$. Although the dependence of healthy food intake, such as fruit and vegetables, on social class has been studied well, the situation is less clear for some of the foods for which significant associations have been described in the present study. Within the ALSPAC (Avon Longitudinal Study of Parents and Children) study ${ }^{(29)}$, a positive association between maternal education and intake of meat products and soft drinks was shown in 18-month-old children.

Table 6 Prevalence of supplement use in boys and girls

\begin{tabular}{|c|c|c|c|c|}
\hline & \multicolumn{2}{|c|}{ Boys } & \multicolumn{2}{|c|}{ Girls } \\
\hline & $n$ & $\%$ & $n$ & $\%$ \\
\hline Number of supplements & \multicolumn{2}{|c|}{ (n 1752) } & \multicolumn{2}{|c|}{$(n 1683)$} \\
\hline 0 & 1631 & $93 \cdot 1$ & 1572 & $93 \cdot 4$ \\
\hline 1 & 101 & $5 \cdot 8$ & 80 & $4 \cdot 8$ \\
\hline$\geq 2$ & 20 & $1 \cdot 1$ & 31 & $1 \cdot 8$ \\
\hline \multicolumn{5}{|l|}{ Frequency } \\
\hline Regular supplement use & 121 & $6 \cdot 9$ & 111 & $6 \cdot 6$ \\
\hline Irregular supplement use & 161 & $9 \cdot 2$ & 155 & $9 \cdot 2$ \\
\hline Specification (only regular & \multicolumn{2}{|c|}{$(n$ 121) } & \multicolumn{2}{|c|}{$(n 111)$} \\
\hline Multivitamins & 69 & $57 \cdot 0$ & 56 & $50 \cdot 5$ \\
\hline Vitamin C & 26 & $21 \cdot 5$ & 28 & $25 \cdot 2$ \\
\hline Vitamin E & 16 & $13 \cdot 2$ & 13 & $11 \cdot 7$ \\
\hline Vitamin B & 3 & $2 \cdot 5$ & 7 & $6 \cdot 3$ \\
\hline$\beta$-Carotene & 1 & $0 \cdot 8$ & 4 & $3 \cdot 6$ \\
\hline $\mathrm{Ca}$ & 12 & $9 \cdot 9$ & 19 & $17 \cdot 1$ \\
\hline $\mathrm{Mg}$ & 18 & $14 \cdot 9$ & 16 & $14 \cdot 4$ \\
\hline Fluorine & 11 & $9 \cdot 0$ & 19 & $17 \cdot 1$ \\
\hline $\mathrm{Zn}$ & 12 & $9 \cdot 9$ & 13 & $11 \cdot 7$ \\
\hline lodine & 5 & $4 \cdot 1$ & 9 & $8 \cdot 1$ \\
\hline $\mathrm{Fe}$ & 4 & $3 \cdot 3$ & 8 & $7 \cdot 2$ \\
\hline Others & 35 & $28 \cdot 9$ & 30 & $27 \cdot 0$ \\
\hline
\end{tabular}

*Multiple answers possible.
Compared with school age, food choice at this age is completely under the control of parents, which is why parental socio-economic position might have a different effect than later in childhood.

Several possible limitations of the study should be considered. First, it should be noticed that the present findings are based on a cross-sectional analysis within the two cohort studies - LISAplus and GINIplus. Even though study sampling was primarily population-based, the study population is, as almost every cohort study, subject to selection bias, and thus the findings are not representative for Germany. Owing to non-random loss to follow-up, both cohorts on which the present analysis is based underrepresent children from lower social classes. The true social inequalities might therefore even be stronger than reported here. Furthermore, the intakes of a large number of nutrients and foods were examined, many of which are correlated with one another. As a result there is the possibility of type I errors occurring. However, the significant associations that we have found are either similar to previous findings or are in line with our previous hypothesis, which leads us to believe that they are unlikely to be the result of type I error. Certainly, it has to be considered that the FFQ was actually not designed to measure, for example, carbohydrate and protein intakes. However, since total energy intake as well as the percentage contribution to total daily energy intake of carbohydrates and protein shows plausible values, we think that this justifies the analysis of the respective macronutrients. However, it has to be considered that the food item list included only those foods that significantly contribute to the intake of total energy, fatty acids and selected antioxidants.

Unfortunately, we do not have any information on whether fortified foods were consumed. However, according to a recent publication ${ }^{(30)}$, the contribution of fortified foods to total nutrient intake is rather low in Germany, in particular for vitamins E and A. The authors further conclude that the base diet is the major contributor to intakes of all nutrients in Europe. When we included nutrients from supplement intake in our analyses, the numbers did not change substantially, as the rather low frequency of regular supplement use in our study population $(<7 \%)$ let assume. However, the rather

Table 7 Results of logistic regression models of parental education and equivalent income on children's supplement use

\begin{tabular}{|c|c|c|c|c|c|c|c|c|c|c|c|c|}
\hline & \multicolumn{6}{|c|}{ Parental education } & \multicolumn{6}{|c|}{ Equivalent income } \\
\hline & \multicolumn{2}{|c|}{ Low $(n$ 193) } & \multicolumn{2}{|c|}{ Medium ( $n$ 888) } & \multicolumn{2}{|c|}{ High (n 2236) } & \multicolumn{2}{|c|}{ Low (n 335) } & \multicolumn{2}{|c|}{ Medium ( $n$ 699) } & \multicolumn{2}{|c|}{ High (n 2401) } \\
\hline & $n$ & $\%$ & $n$ & $\%$ & $n$ & $\%$ & $n$ & $\%$ & $n$ & $\%$ & $n$ & $\%$ \\
\hline \multirow[t]{3}{*}{ User $v$. non-user } & 9 & $4 \cdot 7$ & 66 & $7 \cdot 4$ & 153 & $6 \cdot 8$ & 25 & $7 \cdot 5$ & 47 & $6 \cdot 7$ & 160 & $6 \cdot 7$ \\
\hline & & & $\mathrm{aOR}^{*}$ & $95 \% \mathrm{Cl}$ & $\mathrm{aOR}^{*}$ & $95 \% \mathrm{Cl}$ & & & $\mathrm{aOR}^{\star}$ & $95 \% \mathrm{Cl}$ & $\mathrm{aOR}^{*}$ & $95 \% \mathrm{Cl}$ \\
\hline & \multicolumn{2}{|c|}{$1 \cdot 00$} & 1.62 & $0.83,3.55$ & $1 \cdot 48$ & $0 \cdot 78,3 \cdot 18$ & \multicolumn{2}{|c|}{$1 \cdot 00$} & $0 \cdot 89$ & $0.54,1.50$ & $0 \cdot 88$ & $0.58,1.40$ \\
\hline
\end{tabular}

aOR, adjusted OR.

${ }^{*}$ Adjusted for gender, study centre and age. 
vague estimation of nutrient intake from supplements and the missing information on fortified foods could have led to misclassification of nutrient intake. However, the statistical models for the association between socioeconomic factors and region on food intake are not affected by this matter.

One of the major strengths of the present study was the food selection method underlying the dietary assessment method as described previously ${ }^{(14)}$. In brief, this newly developed FFQ was designed for the specific purpose of measuring diet, especially fatty acid and antioxidant intake, in school-age children. The food selection method was based on a regression approach using data from 9-11-year old children from the German DONALD Study. The FFQ has been validated against one $24 \mathrm{~h}$ dietary recall and has shown good practicability in the past. In summary, even if the FFQ is generally believed to overestimate dietary intakes ${ }^{(31)}$, we believe that this FFQ is valid to rank individuals according to their dietary intakes and to detect differences between levels of socio-economic status. Furthermore, this is one of the few studies in children collecting specific information on dietary supplement use.

In conclusion, we have found that food intake in school-age children differs by the level of parental education and area of living, but the differences cannot be attributed to healthy or unhealthy dietary habits. This suggests that particular efforts should be made to adjust nutrition education programmes to the target population characterised not only in terms of education but also by considering regional particularities.

\section{Acknowledgements}

The present study has been carried out partially with financial support from the Commission of the European Communities, within the FP 6 priority 5.4.3.1 Food quality and safety (Early nutrition programming - long-term follow-up of efficacy and safety trials and integrated epidemiological, genetic, animal, consumer and economic research, EARNEST, Food-CT-2005-007036). This research was supported by 'Kompetenznetz Adipositas (Competence Network Obesity)' and NGFNplus funded by the Federal Ministry of Education and Research (FKZ: 01GI0826, 01GI0823, 01GS0820). Personal and financial support by the Munich Center of Health Sciences (MCHEALTH), which contributed to this research, is gratefully acknowledged. None of the authors have any conflict of interest. S.S. and M.S. were responsible for data analysis, interpretation of data and manuscript preparation and contributed equally to the manuscript; A.B., P.R., S.K., I.L. and J.H. assisted in the interpretation of results and critical revision of the manuscript; C.P.B., B.S., A.v.B., D.B., M.B., O.H., I.L., U.K., H.-E.W. and J.H. were responsible for data collection; S.S., M.S. and J.H. developed the design and analysis plan of the present study. The authors thank all the families for their participation.

\section{References}

1. Winkler G, Brasche S \& Heinrich J (1997) Trends in food intake in adults from the city of Erfurt before and after the German reunification. Ann Nutr Metab 41, 283-290.

2. Mensink GB \& Beitz R (2004) Food and nutrient intake in East and West Germany, 8 years after the reunification The German Nutrition Survey 1998. Eur J Clin Nutr 58, 1000-1010.

3. Giskes K, Turrell G, van Lenthe FJ et al. (2006) A multilevel study of socio-economic inequalities in food choice behaviour and dietary intake among the Dutch population: the GLOBE study. Public Health Nutr 9, 75-83.

4. Giskes K, Avendano M, Brug J et al. (2010) A systematic review of studies on socioeconomic inequalities in dietary intakes associated with weight gain and overweight/ obesity conducted among European adults. Obes Rev 11, 413-419.

5. Irala-Estevez JD, Groth M, Johansson L et al. (2000) A systematic review of socio-economic differences in food habits in Europe: consumption of fruit and vegetables. Eur J Clin Nutr 54, 706-714.

6. Lopez-Azpiazu I, Sanchez-Villegas A, Johansson L et al. (2003) Disparities in food habits in Europe: systematic review of educational and occupational differences in the intake of fat. J Hum Nutr Diet 16, 349-364.

7. Darmon N \& Drewnowski A (2008) Does social class predict diet quality? Am J Clin Nutr 87, 1107-1117.

8. Sichert-Hellert W \& Kersting M (2004) Vitamin and mineral supplements use in German children and adolescents between 1986 and 2003: results of the DONALD Study. Ann Nutr Metab 48, 414-419.

9. Six J, Richter A, Rabenberg $\mathrm{M}$ et al. (2008) Dietary supplement use among adolescents in Germany. Results of EsKiMo. Bundesgesundheitsblatt Gesundheitsforschung Gesundheitsschutz 51, 1202-1209.

10. von Berg A, Koletzko S, Grubl A et al. (2003) The effect of hydrolyzed cow's milk formula for allergy prevention in the first year of life: the German Infant Nutritional Intervention Study, a randomized double-blind trial. J Allergy Clin Immunol 111, 533-540.

11. von Berg A, Filipiak-Pittroff B, Kramer U et al. (2008) Preventive effect of hydrolyzed infant formulas persists until age 6 years: long-term results from the German Infant Nutritional Intervention Study (GINI). J Allergy Clin Immunol 121, 1442-1447.

12. Heinrich J, Bolte G, Holscher B et al. (2002) Allergens and endotoxin on mothers' mattresses and total immunoglobulin $\mathrm{E}$ in cord blood of neonates. Eur Respir J 20, 617-623.

13. Zutavern A, Brockow I, Schaaf B et al. (2006) Timing of solid food introduction in relation to atopic dermatitis and atopic sensitization: results from a prospective birth cohort study. Pediatrics 117, 401-411.

14. Stiegler P, Sausenthaler S, Buyken AE et al. (2010) A new FFQ designed to measure the intake of fatty acids and antioxidants in children. Public Health Nutr 13, 38-46.

15. Bohlscheid-Thomas S, Hoting I, Boeing H et al. (1997) Reproducibility and relative validity of food group intake in a food frequency questionnaire developed for the German part of the EPIC project. European Prospective Investigation into Cancer and Nutrition. Int J Epidemiol 26, Suppl. 1, S59-S70.

16. Hartmann BM, Bell S, Vásquez-Caiquedo AL et al. (2005) Der Bundeslebensmittelschlüssel. German Nutrient Data Base. Karlsruhe: Federal Research Centre for Nutrition and Food (BfEL).

17. Kroke A, Manz F, Kersting M et al. (2004) The DONALD Study. History, current status and future perspectives. Eur J Nutr 43, 45-54. 
18. Block G, Woods M, Potosky A et al. (1990) Validation of a self-administered diet history questionnaire using multiple diet records. J Clin Epidemiol 43, 1327-1335.

19. Haraldsdottir J (1993) Minimizing error in the field: quality control in dietary surveys. Eur J Clin Nutr 47, Suppl. 2, S19-S24.

20. Hauser R (1998) Adequacy and poverty among the retired. In Maintaining Prosperity in an Ageing Society. Ageing Working Paper no. 3.2. Paris: OECD.

21. Sausenthaler S, Kompauer I, Mielck A et al. (2007) Impact of parental education and income inequality on children's food intake. Public Health Nutr 10, 24-33.

22. R Development Core Team (2009) $R$ : A Language and Environment for Statistical Computing. Vienna, Austria: R Foundation for Statistical Computing.

23. Mensink GB, Heseker H, Richter A et al. (2007) Ernährungsstudie als KiGGS-Modul (EsKiMo) - Forschungsbericht. Berlin, Paderborn: Robert-Koch Institut, Universität Paderborn.

24. Stahl A, Vohmann C, Richter A et al. (2009) Changes in food and nutrient intake of 6- to 17-year-old Germans between the 1980s and 2006. Public Health Nutr 12, 1912-1923.

25. Turrell G, Hewitt B, Patterson C et al. (2003) Measuring socio-economic position in dietary research: is choice of

\section{Appendix}

\section{GINIplus study group}

Institute of Epidemiology, Helmholtz Zentrum Muenchen, German Research Center for Environmental Health, Neuherberg (Wichmann HE, Heinrich J, Schoetzau A, Popescu M, Mosetter M, Schindler J, Franke K, Laubereau B, Sausenthaler S, Thaqi A, Zirngibl A, Zutavern A, Filipiak B, Gehring U); Department of Pediatrics, Marien-Hospital, Wesel (Berdel D, von Berg A, Albrecht B, Baumgart A, Bollrath C, Büttner S, Diekamp S, Groß I, Jakob T, Klemke K, Kurpiun S, Möllemann M, Neusüss J, Varhelyi A, Zorn C); Ludwig Maximilians University of Munich, Dr von Hauner Children's Hospital (Koletzko S, Reinhard D, Weigand $\mathrm{H}$, Antonie I, Bäumler-Merl B, Tasch C, Göhlert R, Sönnichsen C); Clinic and Polyclinic for Child and Adolescent Medicine, University Hospital Rechts der Isar of the Technical University Munich (Bauer CP, Grübl A, Bartels P, Brockow I, Hoffmann U, Lötzbeyer F, Mayrl R, Negele K, Schill E-M, Wolf B); IUF-Environmental Health Research Institute, Düsseldorf (Krämer U, Link E, Sugiri D, Ranft U).

\section{LISAplus study group}

Institute of Epidemiology, Helmholtz Zentrum Muenchen, German Research Center for Environmental Health, socio-economic indicator important? Public Health Nutr 6 , 191-200.

26. Klocke A (1997) The impact of poverty on nutrition behaviour in young Europeans. In Poverty and Food in Welfare Societies, pp. 224-237 [B Kohler, E Feichtinger, E Barlosius, et al., editors]. Berlin: Sigma.

27. Laitinen S, Rasanen L, Viikari J et al. (1995) Diet of Finnish children in relation to the family's socio-economic status. Scand J Soc Med 23, 88-94.

28. Cooke LJ, Wardle J, Gibson EL et al. (2004) Demographic, familial and trait predictors of fruit and vegetable consumption by pre-school children. Public Health Nutr 7, 295-302.

29. Rogers I \& Emmett P (2003) The effect of maternal smoking status, educational level and age on food and nutrient intakes in preschool children: results from the Avon Longitudinal Study of Parents and Children. Eur J Clin Nutr 57, 854-864.

30. Flynn A, Hirvonen T, Mensink GB et al. (2009) Intake of selected nutrients from foods, from fortification and from supplements in various European countries. Food Nutr Res Suppl. 1, 53.

31. Robinson S, Godfrey K, Osmond C et al. (1996) Evaluation of a food frequency questionnaire used to assess nutrient intakes in pregnant women. Eur J Clin Nutr 50, 302-308.

Neuherberg (Wichmann HE, Heinrich J, Bolte G, Belcredi P, Jacob B, Schoetzau A, Mosetter M, Schindler J, Höhnke A, Franke K, Laubereau B, Sausenthaler S, Thaqi A, Zirngibl A, Zutavern A); Department of Pediatrics, University of Leipzig (Borte M, Schulz R, Sierig G, Mirow K, Gebauer C, Schulze $\mathrm{B}$, Hainich J); Institute for Clinical Immunology and Transfusion Medicine (Sack U, Emmrich F); Department of Pediatrics, Marien-Hospital, Wesel (von Berg A, Schaaf B, Scholten C, Bollrath C, Groß I, Möllemann M); Department of Human Exposure-Research and Epidemiology, UFZCenter for Environmental Research Leipzig-Halle (Herbarth O, Diez U, Rehwagen M, Schlink U, Franck U, Jorks A, Röder S); Department of Environmental Immunology, UFZcenter for Environmental Research Leipzig-Halle (Lehmann I, Herberth G, Daegelmann C); Ludwig Maximilians University Munich, Dr von Hauner Children's Hospital, Department of Infectious Diseases and Immunology (Weiss M, Albert M); Friedrich-Schiller-University Jena, Institute for Clinical Immunology (Fahlbusch B), Institute for Social, Occupational and Environmental Medicine (Bischof W, Koch A); IUF Environmental Health Research Institute, Düsseldorf (Krämer U, Link E, Ranft U, Schins R); Clinic and Polyclinic for Child and Adolescent Medicine, University Hospital Rechts der Isar of the Technical University Munich (Bauer CP, Brockow I, Grübl A); Department of Dermatology and Allergy Biederstein, Technical University Munich (Ring J, Grosch J, Weidinger S). 